\title{
Top 507 India's High-Cited Papers on Covid-19: A Bibliometric Assessment
}

\author{
Shankar Reddy Kolle, BM Gupta*, KK Mueen Ahmed \\ 'Indira Gandhi National Tribal University, Amarkantak, Madhya Pradesh, INDIA. \\ ${ }^{2}$ Formerly with CSIR-NISTADS, New Delhi, INDIA. \\ ${ }^{3}$ Phcog.Net \#17, Cox Town, Bengaluru, Karnataka, INDIA.
}

\begin{abstract}
In this paper, we have collected the data about the 507 high-cited (citations $\geq 25$ ) papers on Covid 19 published by India using Scopus database. Within small span of time many papers have received considerable number of citations. Further we have analyzed in terms of types of papers, major funding agencies, major collaborating countries, prolific authors, productive organizations and cluster analysis of author supplied keywords. Most of the papers were research articles. Department of Science and Technology, Govt. of India has funded considerable numbers of papers on Covid 19 and K. Dhama form Indian Veterinary Research Institute has contributed highest numbers papers and USA was major collaborating country and PGIMER-Chandigarh was most contributing organization. This study will be
\end{abstract}

useful to the scientist/researchers to know the characteristics of high cited papers on Covid- 19 from India.

Key words: India, Covid-19, High-cited papers, Bibliographic characterstics, Bibliometrics, Scientometrics.

Correspondence

Dr. BM Gupta,

Formerly with CSIR-NISTADS, New Delhi 11012.

Email id: bmgupta1@gmail.com

DOI: 10.5530/jyp.2021.13s.70

\section{INTRODUCTION}

The Coronavirus has created an unprecedented situation for medical practitioners, national and local governments, scientists, and even the common public in India. More than 31,613,993 people tested positive for Covid-19 and 423,842 deaths were reported in India. ${ }^{1}$ Considering the severity of the virus, the research activities have accelerated exponentially to find the remedy. As a result of this, in Scopus database more than 11,612 articles are being published on the Covid-19 in India.

Many authors have analyzed the high-cited articles published by India, in areas such as overall science and technology, materials science, computer science and clinical pharmacology. Therefore, this study is conducted to identify the characteristics of 507 high cited papers published from India. The analysis includes identification of types of documents, major funding agency, collaborating countries, distribution of papers by subject category, top contributing organizations, and types of studies.

\section{Literature Review}

Many authors over the past 1-2 years have assessed global and Indian literature on Covid-192-4 using bibliometric methods. In addition, many authors have analyzed the high-cited articles published by India, in areas such as overall science and technology, materials science, computer science and clinical pharmacology. ${ }^{5-8}$ Since no comprehensive study was available on high cited papers on Covid-19 and existing studies on Covid-19 limited in coverage to few hundred records, we decided to undertake such a study. Therefore, the present study is conducted to identify the characteristics of 507 high cited papers published from India. The analysis includes identification of types of documents, major funding agency, collaborating countries, distribution of papers by subject category and type of studies, the top contributing organizations and authors and journals.

\section{Methodology}

We have searched Scopus on $28^{\text {th }}$ July 2021 with following search string: TITLE ("Covid 19" or "2019 novel coronavirus" or "coronavirus 2019" or "coronavirus disease 2019" or "2019-novel CoV" or "2019 ncov" or Covid 2019 or Covid 19 or "Corona virus 2019" or ncov-2019 or ncov2019 or "nCoV 2019" or 2019-ncov or covid-19 or "Severe acute respiratory syndrome coronavirus 2" or "SARS-CoV-2") or KEY ( "Covid 19" or "2019 novel coronavirus" or "coronavirus 2019" or "coronavirus disease 2019" or "2019-novel CoV" or "2019 ncov" or covid 2019 or covid19 or “corona virus 2019" or ncov-2019 or ncov2019 or "nCoV 2019" or 2019ncov or covid-19 or "Severe acute respiratory syndrome coronavirus 2" or "SARS-CoV-2").

As per this, we found 170,309 global papers on Covid-19 and further we restricted the search to papers from India, where we found 11,612 papers. Further, we identified the Indian papers which have received a minimum of 25 citations. It was found that there were 507 Indian papers in Scopus database having received 25 or more citations and these papers have received 37268 citations. Further, we have downloaded 507 high-cited papers along with their bibliographical information, such as authors, title, source, citations, affiliating country, and organization. We have built a database of 507 papers in Microsoft excel and analyzed for the types of papers, funding agency, international collaboration, type of studies, and top contributing authors, organization and journals.

\section{Analysis of Top 507 Indian High-Cited Papers Document Type}

The 507 India's high-cited publications belonged to six types of documents, as displayed in Table 1. Articles constitute the most significant share $(59.76 \%)$ of the total documents, followed by the reviews $(23.87 \%)$, letters $(10.26 \%)$, notes $(3.75 \%)$, editorials $(1.97 \%)$ and conference papers 
Kolle, et al.: Top 507 India's High-Cited Papers on Covid-19: A Bibliometric Assessment

Table 1: Distribution of India's Publications by Document Type.

\begin{tabular}{lcccc}
\hline Document type & TP & TC & CPP & \%TP \\
\hline Articles & 303 & 21546 & 71.10 & 59.76 \\
Reviews & 121 & 10302 & 85.14 & 23.87 \\
Letters & 52 & 2737 & 52.63 & 10.26 \\
Notes & 19 & 1538 & 80.94 & 3.75 \\
Editorials & 10 & 957 & 95.7 & 1.97 \\
Conference Papers & 2 & 188 & 94 & 0.39 \\
Total & 507 & & & \\
\hline
\end{tabular}

$\mathrm{TP}=$ Total papers; TC-Total citations; $\mathrm{CPP}=$ Citations per document

Table 2: Major Funding Agencies Along with Number of High-Cited Publications on Covid-19 in India.

\begin{tabular}{clcc}
\hline S.No. & Name of funding agency & TP & \% TP \\
\hline 1 & $\begin{array}{l}\text { Department of Science and Technology, Govt. } \\
\text { of India }\end{array}$ & 25 & 5 \\
2 & Department of Biotechnology, Govt. of India & 22 & 4 \\
3 & Science and Engineering Board, India & 21 & 4 \\
4 & Indian Council of Medical Research & 11 & 2 \\
5 & $\begin{array}{l}\text { Council of Scientific and Industrial Research, } \\
\text { India }\end{array}$ & 10 & 2 \\
6 & $\begin{array}{l}\text { National Institute of Health, USA } \\
\text { Total funded publications }\end{array}$ & 8 & 2 \\
\hline
\end{tabular}

$(0.39 \%)$. The highest average citation per document were recorded to the editorials (95.70), followed by the conference papers (94.0), reviews (85.14), etc.

\section{Funded Research}

Out of 507 India's high-cited publications, only 105 (20.71\%) publications came out from the support of external supported funded research coming from India and abroad. The top funding agency along with number of high-cited papers on Covid-19 is provided in the Table 2. These 105 funded publications received 8722 citations, averaging 83.0 citation per publication, which is higher than average citations to the total documents in the dataset. The Department of Science and Technology, Govt. of India has funded almost 4\% (25) of the high-cited papers on Covid-19, followed by the Department of Biotechnology, Govt. of India (22 and 4.0\%), Science and Engineering Board, India (21 and 4.0\%) and Indian Council of Medical Research (11 and 2.0\%).

\section{International Collaborative Research}

Out of 507 India's high-cited papers, 235 (46.35\%) publications were contributed with the participation of international collaboration and registered an average of 80 citations per publication. The major India's collaborating countries with numbers of publications are provided in Table 3. The highest numbers of high-cited papers (99) in India's international collaborative publications on Covid-19 was contributed by the USA, followed by the U.K. (74), China (45), Italy (41), etc. The highest average citations per publication were registered by the publications in collaboration with Saudi Arabia (110), followed by China (106) and South Korea (98).

Figure 1 indicates the India's collaboration with other significant countries (represented through the clusters in green and red colour). The higher frequency of collaboration was observed in Cluster 1 with 9 countries
Table 3: Major Countries Collaborating with India.

\begin{tabular}{lccc}
\hline Country & TP & TC & CPP \\
\hline USA & 99 & 7742 & 78 \\
U.K. & 74 & 5602 & 76 \\
China & 45 & 4779 & 106 \\
Italy & 41 & 2724 & 66 \\
Australia & 37 & 2280 & 62 \\
Brazil & 33 & 2235 & 68 \\
Canada & 33 & 2198 & 67 \\
Germany & 32 & 1590 & 50 \\
Spain & 31 & 2494 & 80 \\
South Korea & 28 & 2747 & 98 \\
Saudi Arabia & 28 & 3091 & 110 \\
Switzerland & 16 & 971 & 61 \\
Thailand & 15 & 1140 & 76 \\
\hline
\end{tabular}

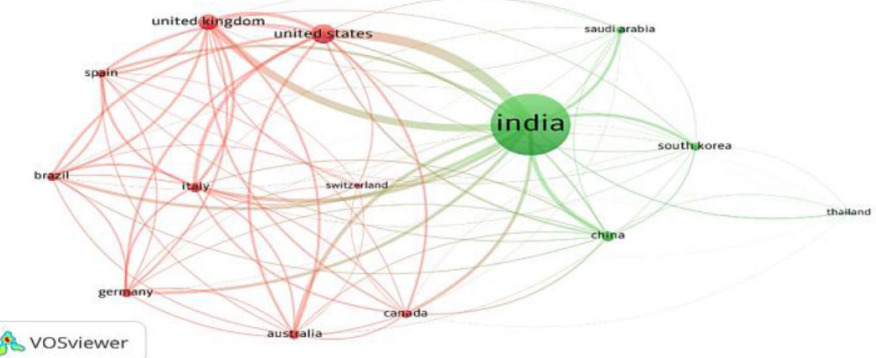

Figure 1: Network Visualization of top 13 Countries with India.

participating and actively collaborating with India like Australia, Brazil, Canada, Germany, Italy, Spain, Switzerland, U.K. and the USA. Cluster 2 includes five countries that vigorously collaborated with India are China, Saudi Arabia, South Korea and Thailand engaged in publishing research on the topic.

\section{Broad Subject-Wise Distribution and Type of Studies}

High-cited publications of India on Covid-19 are categorized under one or more subject categories as defined by Scopus database. The primary subject categories with the number of papers are provided in Table 4 . The largest number of the high-cited papers from India on Covid-19 came from Medicine (311 papers and 61.34\% share), followed by Biochemistry Genetics and Molecular Biology (106 papers and 20.91\% share), Immunology and Microbiology (53 papers and 10.45\% share), Environment Science (51 papers, 10.06\% share), Pharmacology, Toxicology and Pharmaceutics (30 papers, 5.92\% share), Neurosciences (29 papers, $5.72 \%$ share), Psychology (19 papers, 3.75\% share), Computer Science (15 papers, $2.96 \%$ share), Social Sciences (10 papers, $1.97 \%$ share), etc. In terms of impact among various subject categories, Psychology registered the highest citation impact per paper (132.26) and Social Sciences the least (52.5).

India's high-cited papers are also analyzed based on the type of studies and displayed in Table 5. The largest number of studies were categorized under "Treatment" (111 papers, 21.89\% share), followed by "Clinical Studies" (106 papers, 20.91\% share), "Pathophysiology" (69 papers, $13.61 \%$ share), Epidemiology (62 papers, $12.23 \%$ share), etc. In terms of impact, "Clinical Studies" registered the highest citation impact per paper (109.55) and "Treatment" the least (79.50). 
Table 4: Subject-Wise Distribution of High-Cited Papers from India on Covid-19.

\begin{tabular}{cccccc}
\hline S.No & Name of the Subject & TP & TC & CPP & \%TP \\
\hline 1 & Medicine & 311 & 24175 & 77.73 & 61.34 \\
2 & Biochemistry, Genetics and & 106 & 6769 & 63.86 & 20.91 \\
& Molecular Biology & & & & \\
3 & Immunology and Microbiology & 53 & 3589 & 67.72 & 10.45 \\
4 & Environment Science & 51 & 3892 & 76.31 & 10.06 \\
5 & Pharmacology, Toxicology and & 30 & 1633 & 54.43 & 5.92 \\
& Pharmaceutics & & & & \\
6 & Neuroscience & 29 & 1851 & 63.83 & 5.72 \\
7 & Psychology & 19 & 2513 & 132.26 & 3.75 \\
8 & Computer Science & 15 & 905 & 60.33 & 2.96 \\
9 & Social Sciences & 10 & 525 & 52.50 & 1.97 \\
10 & Veterinary Science & 3 & 347 & 115.67 & 0.59 \\
& India’s total high-cited papers & 311 & 24175 & 77.73 & 61.34 \\
\hline
\end{tabular}

Table 5: Type of Studies of India's High- Cited papers of India on Covid-19.

\begin{tabular}{clcccc}
\hline S.No & Type of studies & TP & TC & CPP & \%TP \\
\hline 1 & Treatment & 111 & 8824 & 79.50 & 21.89 \\
2 & Clinical Studies & 106 & 11612 & 109.55 & 20.91 \\
3 & Pathophysiology & 69 & 5321 & 77.12 & 13.61 \\
4 & Epidemiology & 62 & 5658 & 91.26 & 12.23 \\
5 & Genetics & 47 & 3898 & 82.94 & 9.27 \\
6 & Complications & 42 & 3523 & 83.88 & 8.28 \\
7 & Risk Factors & 40 & 3669 & 91.73 & 7.89 \\
& India’s total HCP & 507 & & & \\
\hline
\end{tabular}

\section{Most Prolific authors}

Nine most productive Indian authors who have contributed at least ten or more high-cited publications on Covid-19 are listed in Table 6. Among India's authors, K. Dhama (IVRI-Bareilly) has contributed the highest number (20) of high-cited publications, followed by R. Tiwari and S. Kumar (16 papers each), and A. Kumar (15 papers). Of the 9 Indian most productive1, two authors belonged to Indian Veterinary Research Institute, Uttar Pradesh. The papers published by the A.J. RodriguezMorales and Indian authors have the highest impact, followed by the R. Sah, K. Dhama, and A.K. Singh. A collaboration network of the most prolific authors is performed using VOSviewer software. The authors with eight articles with a minimum of 100 citations were selected for the creations collaboration network (Figure 2). The Figure contains both collaboration between Indian authors and Indian and Foreign authors have contributed 10 or more papers.

\section{Most Productive Organizations}

Table 7 presents the profile of top 15 most productive organizations in Covid-19. PGIMER-Chandigarh has contributed the highest numbers of high-cited papers, followed by the AIIMS-New Delhi (23 papers), IVRIBareilly (22 papers), College of Veterinary Science, Mathura (17), and NIHMANS-Bangalore (15). The highest average citations per paper were recorded to the papers published by the JIPMER-Pondicherry (133.89), followed by the IVRI-Bareilly (112.50), IIT-New Delhi ((4.78), etc.
Table 6: Profile of Most Productive Authors in Covid-19.

\begin{tabular}{|c|c|c|c|c|c|}
\hline S.No & Author & TP & TC & CPP & Institute \\
\hline 1 & K. Dhama & 20 & 2401 & 120.05 & $\begin{array}{l}\text { Indian Veterinary Research } \\
\text { Institute, Bareilly, Uttar Pradesh }\end{array}$ \\
\hline 2 & R. Tiwari & 16 & 1350 & 84.38 & DUVASU, Mathura, India \\
\hline 3 & S. Kumar & 16 & 959 & 59.94 & $\begin{array}{c}\text { Veer Bahadur Singh Purvanchal } \\
\text { University, U.P }\end{array}$ \\
\hline 4 & A.Kumar & 15 & 825 & 55.00 & $\begin{array}{l}\text { All India Institute of Medical } \\
\text { Sciences, Raipur }\end{array}$ \\
\hline 5 & A. Misra & 14 & 1225 & 87.50 & $\begin{array}{l}\text { Fortis C-DOC Center for } \\
\text { Excellence for Diabetes, New } \\
\text { Delhi }\end{array}$ \\
\hline 6 & Y.S. Malik & 12 & 1201 & 100.08 & $\begin{array}{c}\text { Indian Veterinary Research } \\
\text { Institute, UP }\end{array}$ \\
\hline 7 & R. Singh & 12 & 966 & 80.50 & $\begin{array}{c}\text { CSIR-Institute of Himalayan } \\
\text { Bioresource Technology, } \\
\text { Palampur }\end{array}$ \\
\hline 8 & A.K. Singh & 12 & 1337 & 111.42 & $\begin{array}{l}\text { G. D Hospital and Diabetes } \\
\text { Institute, Kolkata }\end{array}$ \\
\hline 9 & R. Vaishya & 10 & 671 & 67.10 & $\begin{array}{l}\text { Indraprastha Apollo Hospital, } \\
\text { New Delhi }\end{array}$ \\
\hline
\end{tabular}

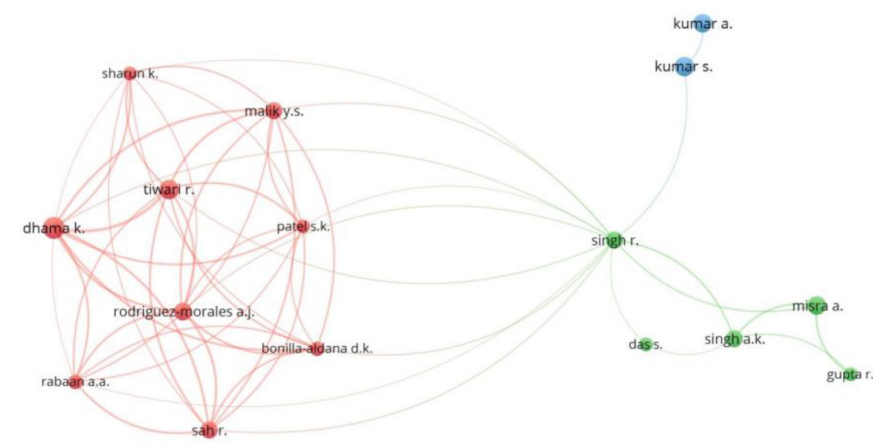

\& vosviewer

Figure 2: Collaboration networks of most prolific authors.

Table 7: Profile of Top 15 Most Productive Indian Organizations in Covid-19.

\begin{tabular}{clccc}
\hline S.No & Name of the Organization & TP & TC & CPP \\
\hline 1 & PGIMER-Chandigarh & 33 & 2055 & 62.27 \\
2 & AIIMS-New Delhi & 23 & 1083 & 47.09 \\
3 & IVRI-Bareilly & 22 & 2475 & 112.50 \\
4 & College of Veterinary Science, Mathura & 17 & 1372 & 80.71 \\
5 & NIHMANS-Bangalore & 15 & 834 & 55.60 \\
6 & K.G. Medical University, Lucknow & 14 & 1012 & 72.29 \\
7 & Jamia Milia Islamia, New Delhi & 14 & 1187 & 84.79 \\
8 & U.P.Pandit Deen Dayal Upadhya Pasu & 13 & 1211 & 93.15 \\
& Chiksalaya, Mathura, U.P. & & & \\
9 & Indraprastha Apollo Hospital & 13 & 797 & 61.31 \\
10 & SGPGIMS-Lucknow & 12 & 526 & 43.83 \\
11 & Manipal Academy of Higher Education & 10 & 689 & 68.90 \\
12 & IIT-New Delhi & 9 & 853 & 94.78 \\
13 & JIPMER-Pondicherry & 9 & 1205 & 133.89 \\
14 & University of Delhi & 8 & 473 & 59.13 \\
15 & Tata Memorial Hospital, Mumbai & 6 & 198 & 33.00 \\
\hline
\end{tabular}




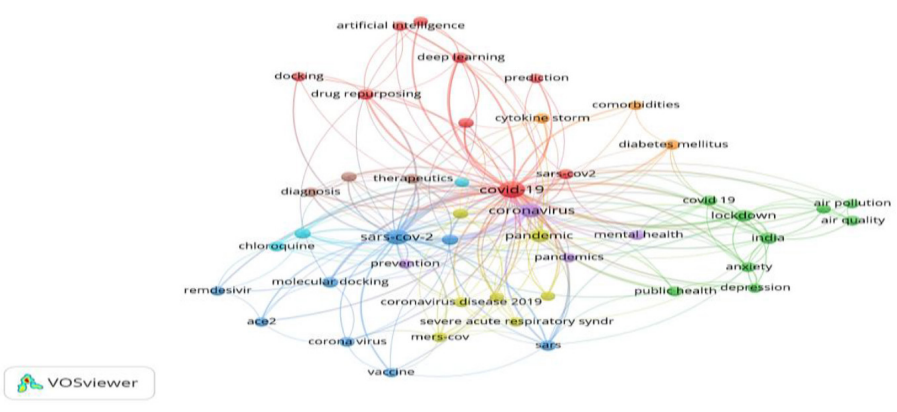

Figure 3: Cluster analysis of author supplied keywords.

\section{Significant Keywords}

Cluster analysis of author-supplied keywords was performed using VOSviewr software. The author supplied keywords that appeared at least five times were selected to see association links between the keywords. The software used found 46 most frequently appeared keywords and performed the cluster analysis of the keywords as provided in Figure 3. Cluster 1 includes the keywords such as artificial intelligence Covid 19, machine learning, prediction, and deep learning. Cluster 2 includes air pollution, air quality, anxiety, depression, lockdown, PM2.5, and public health. Cluster 3. Coronavirus molecular docking, remdesivir, vaccine. Cluster 4 coronavirus, pandemic, transmissions, quarantine. Cluster 5 includes coronavirus, mental health, pandemic, and prevention. Cluster 6. Chloroquine, diabetes, and hydroxychloroquine. Cluster 7 includes comorbidities, Cytokine storm, diabetic millets, and Cluster 8 includes diagnosis, therapeutics, and vaccine.

\section{CONCLUSION}

In this paper, we have analyzed the high-cited papers of India (receiving 25 or citations) on Covid-19. The analysis includes types of papers, major funding agencies, major collaborating countries, types of studies and identification of leading organizations and authors. The majority of the papers were research articles, and the surprising finding is that the highest average citations were recorded to the Editorials. Department of Science and Technology, Govt. of India and Department of Biotechnology, Govt. of India are the significant funder towards the Covid-19 research in India. USA and UK were significant collaborators in the Covid-19 research, and PGIMER-Chandigarh has contributed the highest number of papers. The cluster analysis of author-supplied keywords indicates that a significant portion of the research was concerned with air pollution and air quality effect on Coronavirus pertinent and psychological issues faced by the citizen during the lockdown in India.

\section{REFERENCES}

1. Covid in India https://www.worldometers.info/coronavirus/country/india/.

2. Pathak M. Covid-19 research in India: A quantitative analysis. Indian J Biochem Biophys. June 2020;57(3):351-5.

3. NVR, Patil SB. Indian Publications on SARS-CoV-2: A bibliometric study of WHO Covid-19 database. Diabetes Metab Syndr. 2020;14(5):1171-8. doi: 10.1016/j. dsx.2020.07.007. PMID 32673837.

4. Ghosh TK. Bibliometric landscape of Indian publications on Covid-19 in 2020 Library Philosophy and Practice (e-journal). Available from: https://digitalcommons.unl.edu/libphilprac/5814. Vol. 5814; 2021.

5. Elango B, Ho Y-S. A bibliometric analysis of highly cited papers from India in Science Citation Index Expanded. Curr Sci. April 25 2017;112(8):1653-8. doi: 10.18520/cs/v112/i08/1653-1658.

6. Gupta BM, Dhawan SM, Gupta R. Highly cited publications output by India in materials science published during 2003-2012: A scientometric assessment. J Scientometr Res. 2015;4(3):178-94. doi: 10.4103/2320-0057.174859.

7. Gupta BM, Dhawan SM. Highly Cited Publications Output by India in Computer Science 1996-15: A Scientometric Assessment. J Scientometr Res. 2017;6(2):74-85. doi: 10.5530/jscires.6.2.13.

8. Ahmed KKM, Dhawan SM, Gupta BM, Bansal M. Highly cited publications output by India in clinical pharmacology during 2000-14: A scientometric assessment. J Young Pharm. 2017;9(2):145-7. doi: 10.5530/jyp.2017.9.30. 